systemic blood pressure were normal. She was given oxygen. Her blood glucose concentration was $3 \mathrm{mmol} / \mathrm{l}$, and it did not improve after injection of $20 \mathrm{ml} 50 \%$ dextrose solution intravenously. Naloxone $0.4 \mathrm{mg}$ by slow intravenous injection evoked restlessness and movement of the arms and legs and her pupils dilated and reacted sluggishly to light. The pattern of her breathing did not change; stupor rapidly returned, and the pupils constricted. Twenty minutes later physostigmine $2 \mathrm{mg}$ intravenously in divided doses was given empirically. Her pupils rapidly dilated and became reactive with a consensual reflex, her temperature rose, and normal breathing was restored. Although confused, she could converse. Thereafter postoperative recovery was uneventful.

Cheyne-Stokes respiration is commonly a harbinger of death. Variously ascribed to poor systemic circulation, raised intracranial pressure, impaired lung dynamics, and reduced sensitivity of the brain stem to hypoxia, ${ }^{3}$ the condition lacks a truly scientific rationale. General anaesthesia has been incriminated but not spinal analgesia, ${ }^{4}$ and the cause of Cheyne-Stokes respiration in our patient remains obscure.

Although Cheyne-Stokes respiration can revert to normal breathing without treatment, we conclude in this case that reversion was synchronous with and related to the empirical use of physostigmine. If that is so Cheyne-Stokes respiration in our patient may have been the result of a deficit in her cholinergic system. Dr Byrne and Professor Arie stated that "there are good reasons why manipulating the cholinergic system might be effective in treating Alzheimer's disease." One swallow does not make a summer, but little harm and possible good may come from manipulating the cholinergic system in patients with Cheyne-Stokes respiration of obscure aetiology.

P V SCOTT

Department of Anaesthetics,

Alexandra Hospital, Redditch,

Worcestershire B98 7UB

1 Byrne J, Arie T. Tetrahydroaminoacridine (THA) in Alzheimer's disease. Br Med f 1989;298:845-6. (1 April.)

2 Teasdale G, Jennett B. Assessment of coma and impaired consciousness: a practical scale. Lancet 1974;ii:81-3.

3 Wood P. Diseases of the heart and circulation. 3rd ed. London Eyre and Spottiswoode, 1968:315-6.

4 Vandam LD, Dripps RD. Longterm follow up of patients wh received 10,098 spinal anaesthetics. FAMA 1956;161:586-91.

\section{Does constitutional hypotension exist?}

SIR,-Dr John Pemberton's recent article highlights the interesting problem of constitutional hypotension' and whether this should be recognised as a disease and treatment given to increase blood pressure.

Common symptoms include giddiness, blackouts, and fainting, all of which occur with changes in posture and resultant cerebral hypoperfusion. ${ }^{2}$ To investigate the relation of the above symptom to blood pressure we recently asked 71 elderly patients (aged 65-90 years) attending a day hospital to fill in a questionnaire regarding symptoms of giddiness, blackouts, and fainting. With the results unknown to the examiner blood pressure was recorded supine and again erect after two minutes' standing using a Hawksley random zero sphygmomanometer. Seventeen $(24 \%)$ admitted to one or more of the above symptoms. There was no relation between supine systolic blood pressure and symptoms (eight patients had a systolic blood pressure $>11 \mathrm{~mm} \mathrm{Hg}$, of whom only two had symptoms and both had a postural fall in systolic blood pressure $>20 \mathrm{~mm} \mathrm{Hg}$ ). Moreover, 12 of the 17 symptomatic versus 11 of the 54 asymptomatic patients showed a postural fall in systolic blood pressure greater than $20 \mathrm{~mm} \mathrm{Hg}(\mathrm{p}<0.001$, $\left.\chi^{2}=12 \cdot 7\right)$. These results suggest that the postural fall in blood pressure rather than constitutional hypotension was the main cause of symptoms. Therefore, we strongly support Dr Pemberton's conclusions that at the present time there are insufficient data to support the view of constitutional hypotension as a separate disease. We believe that treatment in patients with low blood pressure should be reserved only for those who have symptoms of postural cerebral hypoperfusion after lying and standing blood pressures have been recorded and should be given only after other medical causes have been excluded.

D HESELTINE M G BRAMBLE

Hull Royal Inifirmary,

Hull HU3 $2 \mathrm{JZ}$

1 Pemberton J. Does constitutional hypotension exist? Br Med $\mathcal{J}$ 1989;298:660-2. (11 March.)

2 Wollner L, McCarthy ST, Soper NDW, Macy DJ. Failure of cerebral auto-regulation as a cause of brain dysfunction in the elderly. BrMed f 1979;i:117-8.

\section{Percutaneous balloon valve dilatation}

SIR, - In their editorial Drs Marc J Levine and Raymond G McKay stated that advanced age is a sufficient risk factor for mitral valve replacement to warrant balloon valvuloplasty as the preferred first line treatment for mitral valve stenosis.' Assuming that by advanced age they were referring to patients over 70 , I would like to clarify the position of mitral valve replacement in this population.

Most elderly patients are referred for mitral valve replacement after prolonged medical treatment and preoperatively are classified as New York Heart Association functional class IV. Kay $e t$ $a l$ have noticed that "much of the great mortality associated with mitral valve replacement in the elderly was due to the practice of withholding valve replacement from patients until they were end stage IV cardiac cripples;" their series of $\mathbf{3 0}$ functional class III patients gave an early mortality of about $3 \%$. $^{2}$ This compares closely with mortality of $3 \%$ for the under 65 population. ${ }^{3}$ There is also great variation among surgical centres, mortality in some varying between $20 \%$ and $57 \%$ ts and in others between $5 \%$ and $12 \%,{ }^{6-8}$ many of these patients being in functional class IV at surgery. In the elderly population most deaths and failure to improve after a mitral valve replacement are a consequence of intrinsic myocardial disease rather than valve related problems, which tend to be the main contributors in those under $65 .^{\circ}$ Elderly patients surviving the operation achieve functional improvement similar to the under 65 population, $90 \%$ improving by one to two functional classes. ${ }^{1011}$ Therefore, the evidence to date suggests that mitral valve replacement will benefit the elderly and should be offered while the patient still has reasonable myocardial function, ideally not worse than that in class III. Age should not be grouped with severe pulmonary hypertension and biventricular failure as a high risk factor for mitral valve replacement.

St Mary's Hospital,

London W2 INY

1 Levine MJ, McKay RG. Percutaneous balloon valve dilatation. Br Med f 1989;298:620-1. (11 March.)

2 Kay HR, Goel IP, Mundth ED. Valve replacement in the elderly: special consideration and results. Geriatrics 1982;37:109-14.

3 Adler DS, Goldman L, O'Neil A, et al. Long term survival of more than 2,000 patients after coronary artery bypass grafting. Am f Cardiol 1986;58:195-209.

4 Stephensen LW, MacVaugh H, Edmunds LH. Surgery using cardiopulmonary bypass in the elderly. Circulation 1978; 58:250-4

5 Barnhorst DA, Giuliani ER, Pluth JR, Danielson GK, Wallace $\mathrm{RB}$, McGoon DC. Open heart surgery in patients more than RB, McGoon DC. Open heart surgery in paie
65yrs old. Ann Thorac Surg 1974;18::81-90.

6 Hamby RI, Wisoff BG, Kolker P, Hartstein M. Intractable angina pectoralis in the 65 to 79 year age group: a surgical approach. Chest 1973;64:46-50.

De Bono AHB, English TAH, Milstein BB. Heart valve replacement in the elderly: encouraging postoperative clinical and haemodynamic results. Br Med F 1978;ii:917-9.

8 Canepa-Anson R, Emmanuel R W. Elective aortic and mitral valve surgery in patients over 70 yrs of age. Br Heart $\mathcal{J}$ valve surgery
$1979 ; 41: 493-7$.

9 Leguerrier A, Logeaist, Rioux C, et al. Aortic valve replacement in persons over 75. Presse Med 1988:17:147-50.

10 Hochberg MS, Derkac WM, Conkle DM, McIntosh CL, Epstein SE, Morrow AG. Mitral valve replacement in elderly patients: encouraging postoperative clinical and hemodynamic results. F Thorac Cardiovasc Surg 1978;77:422-6.

11 Pelletier LC, Castonguay TR, Chaitman BR. Open-heart surgery in elderly patients. Can Med Assoc $\mathcal{F}$ 1983;128:409-12.

\section{India in $\mathrm{AD} 2001$}

SIR,-Professor Sunil K Pandya referred to the formation of a Science Advisory Council to the Prime Minister of India to advise the government on planning for AD 2001.' Among other activities the council has been requested to help the country meet the basic needs of every person: food, housing, health, employment, and education.

Social and health indicators for Kerala and India (latest figures available)

\begin{tabular}{lcc}
\hline Indicator & Kerala & India \\
\hline Birth rate & $22 \cdot 4$ & 33.6 \\
Crude death rate: & $6 \cdot 7$ & $9 \cdot 0$ \\
$\quad$ Urban & $7 \cdot 1$ & $15 \cdot 1$ \\
$\quad$ Rural & 27.0 & 96.0 \\
Infant mortality rate & $67 \cdot 0$ & $55 \cdot 0$ \\
Life expectancy at birth: & 70.0 & $54 \cdot 0$ \\
$\quad$ Men & \\
$\quad$ Women & $75 \cdot 26$ & 46.89 \\
Adult literacy rate: & $65 \cdot 73$ & 24.82 \\
$\quad$ Men & \\
$\quad$ Women & & \\
\hline
\end{tabular}

Sources: Health Profile Kerala, Department of Health and Family Welfare (1983), and Statistics for Planning, Department of Economics and Statistics (1986), Trivandrum, Kerala.

In this context I wish to point out that the state of Kerala in India has already achieved remarkable success in improving the health of its people. ${ }^{2}$ Kerala is poor even by Indian standards with an income per head substantially lower than the all India average. ${ }^{3}$ The table gives some of the basic indicators for the state of Kerala and for all India which illustrate the success achieved. The experience of Kerala would certainly be of use to Indian planners.

K BALASUBRAMANIAM

International Organisation of Consumers Unions,

10830 Penang,

Malaysia

1 Pandya SK. India in AD 2001: the role of science and technology. Br Med f 1989;298:685. (11 March.)

2 World Health Organisation. Intersectoral action for health: the role of intersectoral cooperation in national strategies for Health for All. Geneva: World Health Organisation, 1986:27-30.

3 Morley D, Rohde J, Williams G. Practising health for all. Oxford Oxford University Press, 1983:65

\section{Merit awards- $\$ 100 \mathrm{~m}$ management tool}

SIR, - About a third of the annual $£ 72 \mathrm{~m}$ for merit awards is spent each on $\mathrm{C}, \mathrm{B}$, and $\mathrm{A}$ plus $\mathrm{A}+$ awards. I have been puzzled by the white paper's failure to grasp this opportunity to reform merit awards more effectively as a carrot for NHS work (including, of course, teaching and research). This is one area where the government could and should have been more radical and imaginative. One of the supposed changes proposed-to restrict progression to the remaining three levels to $\mathrm{C}$ award holders - is indeed not a change at all.

At present the system ostensibly tries to reward excellence in clinical, administrative, and academic work. It is not considered to be relevant how much 